\title{
Pregnancy complications and adverse birth outcomes
}

\section{among women with coeliac disease: A population-based}

\section{study from England}

\author{
Alyshah Abdul Sultan ${ }^{1}$, Laila J Tata ${ }^{1}$, Kate M Fleming ${ }^{1}$, Colin Crooks ${ }^{1}$, Jonas \\ F Ludvigsson $^{24}$, Nafeesa N Dhalwani ${ }^{1}$, Lu Ban ${ }^{1}$, Joe West ${ }^{1}$ \\ ${ }^{1}$ Division of Epidemiology and Public Health, University of Nottingham, Clinical Sciences \\ Building, City Hospital, Hucknall Road, Nottingham, UK, NG5,1PB \\ ${ }^{2}$ Department of Medical Epidemiology and Biostatistics, Karolinska Institute, Stockholm, \\ Sweden \\ ${ }^{4}$ Dept Paediatrics, Örebro University Hospital, Örebro, Sweden \\ Funding: CORE/Coeliac UK
}

Address for Correspondence: Alyshah Abdul Sultan, Division of Epidemiology and Public Health, School of Community Health Sciences, University of Nottingham, Clinical Sciences Building, City Hospital, Nottingham, UK, NG5 1PB

Email: alyshah_abdul_sultan@nottingham.ac.uk

Word Count (manuscript) $=3,800$

Word Count $($ Abstract $)=250$

Tables $=5$

References $=23$

Keywords= Coeliac disease pregnancy complications adverse birth outcomes 


\begin{abstract}
Objective

Evidence-based information about adverse birth outcomes and pregnancy complications is crucial when counselling women with coeliac disease (CD), however, limited populationbased data on such risks exist. We estimated these for pregnant women with CD diagnosed before and after delivery.
\end{abstract}

\title{
Design
}

We included all singleton pregnancies between 1997-2012 using linked primary care data from the Clinical Practice Research Datalink (CPRD) and secondary care Hospital Episode Statistics (HES) data. Risks of pregnancy complications (antepartum and postpartum haemorrhage, pre-eclampsia and mode of delivery) and adverse birth outcomes (preterm birth, stillbirth and low birth weight) were compared between pregnancies of women with and without $\mathrm{CD}$ using logistic/multinomial regression. Risks were stratified based on whether women were diagnosed or yet undiagnosed before delivery.

\section{Results}

Of 363,930 pregnancies resulting in a live birth or stillbirth, $892(0.25 \%)$ were among women with CD. Diagnosed CD was not associated with an increased risk of pregnancy complications or adverse birth outcomes compared to women without CD. However, the risk of postpartum haemorrhage was slightly higher among pregnant women with diagnosed CD (adjusted Odds Ratio $(\mathrm{aOR})=1.34$ 95\%CI;1.04-1.72). We found no increased risk of any pregnancy complication among those with undiagnosed CD. We only observed $1 \%$ absolute excess risk of pre-term birth and low birth weight among undiagnosed CD mothers corresponding to $\mathrm{aOR}=1.24 \quad(95 \% \mathrm{CI} ; 0.82-1.87)$ and $\mathrm{aOR}=1.36 \quad(95 \% \mathrm{CI} ; 0.83-2.24)$ respectively.

\section{Conclusion}

Whether diagnosed or undiagnosed during pregnancy, CD is not associated with a major increased risk of pregnancy complications and adverse birth outcomes. These findings are reassuring to both women and clinicians. 


\section{What is current knowledge?}

- About 10 in 1000 pregnant women could have some form of latent or undetected CD and that about 2 in 1000 deliveries per year in the UK will be in women with known coeliac disease.

- There is lack of evidence on the risk of pregnancy complications among women with $\mathrm{CD}$

- Most studies done on the subject often suffer from either selection bias or inadequate power which limits the generalisability of the study findings.

\section{What is new here?}

- Most women with $\mathrm{CD}$ diagnosed either before or after pregnancy will have a pregnancy and delivery that is not complicated by an adverse event.

- Women with diagnosed with CD may have a slightly increased risk of postpartum haemorrhage but the reasons for this are not clear. 


\section{Introduction}

Subclinical pathological evidence of coeliac disease (CD) is present in around $1 \%$ of most European populations(1) of which approximately $0.2 \%$ have been clinically diagnosed with CD.(2) This suggests that about 10 in 1000 pregnant women could have some form of latent or undetected CD and that about 2 in 1000 deliveries per year in the UK will be in women with known CD. Given this estimated prevalence and the potential adverse physiological effects CD might engender it is surprising that so few good studies have been produced that have tried to quantify the risks to the mother and the child around delivery. The studies(3-9) that have tried to quantify the risks of pregnancy and delivery related adverse events among women with $\mathrm{CD}$ can be categorised broadly as either case-series of individuals, in single or multiple centres pooled together, or registry-based. Most case-series $(4,10,11)$ have been based on a small number of pregnant women with known CD (i.e. <150) or pregnant women who are screened for positive serology leading to the identification of a small number of women with previously undiagnosed CD. Unsurprisingly the results are conflicting; for example Martinelli et al(11) reported that the 12 pregnant women they found to have undiagnosed $\mathrm{CD}$ were more likely to have babies with low birth weight compared to those who were serology negative; however, a similar study based on 52 undiagnosed cases from multiple centres found no excess risk of low birth in offspring.(10) Far larger studies from Sweden and Denmark, $(7,8)$ have used in-patient national registries to identify women with $\mathrm{CD}$ which provide greater number of women, however, appear to underestimate the prevalence of $\mathrm{CD}$. This may explain their findings of an increased risk of some adverse birth outcomes for both mother (caesarean section) and child (low birth weight, intrauterine growth restriction $)(7,8)$ if the populations they have studied were not generalisable to all women with CD. 
It appears therefore that accurate contemporary estimates of the risk of adverse birth outcomes among women with undiagnosed and diagnosed $\mathrm{CD}$ that are generalisable to the majority are absent. We have carried out a population-based cohort study using primary and secondary healthcare data from England with the aim of quantifying the risks of pregnancy complications and adverse birth outcomes among women with CD. 


\section{Methods}

\section{Study population}

We used the Clinical Practice Research Datalink (CPRD) (12) which is a large longitudinal UK database of computerised primary care (i.e. general practice) records. The vast majority of the UK population is registered with general practitioners (GPs), who are responsible for overseeing a patient's medical care which includes coordination of their health care from hospital or other secondary care facilities. The CPRD includes practices that have met training standards in their recording of clinical information using Vision software and who have consented to be included in the database.(13) All patients within a consented practice are automatically included.

Around 53\% of the CPRD practices are linked to Hospital Episode Statistics (HES)(14) data which contain information on all hospitalisations in England including all discharge diagnoses and procedures. The anonymised patient identifiers from CPRD and HES were linked by a trusted third party using the National Health Service (NHS) number, date of birth, postcode and gender.(15) First, patients were matched exactly according to the NHS number (over $90 \%$ of patients are linked in this way), with the remaining patients linked probabilistically on the basis of postcode, date of birth and gender As HES only covers English hospitals, practices from Northern Ireland, Wales and Scotland were excluded. Previously, data from the linked portion of the CPRD have been shown to be broadly representative in terms of age and sex distribution to data from the UK population published by the Office for National Statistics (ONS).(16) We identified all singleton pregnancies recorded in HES between 1997 and 2012 that ended in a live birth or a stillbirth among women aged 15-44 years as our study population. We therefore had prospectively recorded health and socio-demographic information for women before, during and after pregnancy. 
Mothers with CD were defined as those with a medical Read code for a diagnosis of CD in their primary care records (including Read code J690.00 CD, J690.13 Gluten enteropathy, J690.14 Sprue-nontropical, J690100 Acquired CD and J690z00 CD NOS). We did not include women who had diagnoses of dermatitis herpetiformis (DH), however, women with both diagnoses $(\mathrm{CD}$ and $\mathrm{DH})$ were retained in the $\mathrm{CD}$ group. Each woman with $\mathrm{CD}$ was assigned a date of diagnosis corresponding to the date of her first record of $\mathrm{CD}$ or the date of her first prescription of a gluten-free product. These women were then classified as having the $\mathrm{CD}$ diagnosis before delivery (diagnosed $\mathrm{CD}$ ) or afterwards (undiagnosed CD) for each pregnancy in the study. Pregnancies among women with a recorded history of CD prior to the study start date were included in the diagnosed CD group. The method we used for defining $\mathrm{CD}$ has been validated in general practice databases with the positive predictive value ranging between $81 \%$ and $89 \% .(2)$

Pregnancies where women's first diagnosis of CD was recorded in the 12 weeks postpartum were also included in the diagnosed CD group. We used this conservative approach firstly to include women who may have had well-controlled CD not requiring medical/GP contact before or during pregnancy but whose postpartum follow-up may have resulted in a recorded diagnosis; and secondly the diagnostic work-up/process for CD may be long and therefore these are unlikely to be new diagnoses.

Our comparison group consisted of pregnant women without any recorded diagnoses of CD or DH in their primary or secondary care data. Pregnant women who received a gluten-free prescription in the absence of any $\mathrm{CD}$ or DH diagnosis at any point during the study period were also excluded. 


\section{Defining outcomes}

We extracted information on pregnancy complications which included postpartum haemorrhage, antepartum haemorrhage and pre-eclampsia/eclampsia based on ICD-10 codes from secondary care. Mode of delivery was categorised as normal vaginal delivery, assisted vaginal delivery (forceps, breech or vaccuum), emergency or elective caesarean section. Information on length of gestation was categorised as normal (37-42 weeks), pre term $(<37$ weeks) or prolonged (>42 weeks) whereas infant's birth weight was categorised as normal (2500-4500 grams), low birth weight (>2500 grams) or macrosomia (<4500 grams). We also analysed birth weight as a continuous variable. Finally we also extracted information on pregnancies resulting in stillbirths.

\section{Defining maternal co-variables}

For each pregnancy, information on maternal factors during or before pregnancy was extracted from the women's medical records. Maternal age at delivery was categorised into six age groups $(15-19,20-24,25-29,30-34,35-39$ and 40-44 years) whereas calendar year was considered in three categories (1997-2001, 2002-2007 and 2007-2012). Information on body mass index (BMI) (the latest measure recorded by the general practitioner before the estimated date of conception categorised according to World Heath Organisation classification), smoking status (the latest measure recorded by the GP before delivery) and ethnicity (as recorded in HES and categorised as white or non-white(17)) was also extracted. Socioeconomic status (SES) defined as the area in which the general practice is located, at which the patient was registered (quintiles by rank of Indices of Multiple Deprivation(18)). Pregnant women were also defined as having diabetes (pre-existing type 1 or type 2 ) if it was recorded either in primary or secondary care data, or they had received a prescription for an anti-diabetic medication (insulin or oral hypoglycaemic agents) any time before delivery. 


\section{$\underline{\text { Statistical analysis }}$}

We calculated the proportions of pregnancies with complications or adverse birth outcomes that occurred in women with and without a diagnosis of CD. These proportions were then stratified by the status of the pregnancy with respect to having diagnosed or undiagnosed CD. We used logistic regression to calculate odds ratios (OR) and 95\% Confidence Intervals (95\% CI) to assess the associations of $\mathrm{CD}$ overall, diagnosed $\mathrm{CD}$ and undiagnosed $\mathrm{CD}$ with each pregnancy complication and adverse birth outcome. For categorical outcomes (e.g. mode of delivery), multinomial logistic regression was used and relative risk ratios (RRRs) and corresponding 95\% CIs were calculated. These estimates were adjusted for all potential confounders: maternal age, BMI, smoking status, diabetes, ethnicity, calendar year and socioeconomic status. Missing information on BMI, smoking status and birth weight was categorised as a separate category and included in the analysis. We used linear regression to calculate the mean grams of difference in the birth weight of infants born to women with CD compared with those born to women without CD while adjusting for all co-variables. As some women experienced more than one pregnancy during the study period, a clustering term (in our regression models) was fitted. For the purpose of this study, we only considered pregnancy complication or adverse birth outcome to be truly associated with $\mathrm{CD}$ if we observed an absolute risk difference (between women with and without CD) of $3 \%$ or more. All outcomes with the absolute risk difference of less than $3 \%$ where considered to be within the random variation of the data.

\section{$\underline{\text { Sensitivity analyses }}$}

We undertook four additional analyses to ensure the robustness of our results. Firstly, we repeated our analysis by restricting the group of women with $\mathrm{CD}$ to only those who had 
received a gluten-free prescription to increase the specificity of our disease definition. Secondly, we assessed the extent to which women had only hospital recordings of CD using ICD-10 codes (K90.0) (with no evidence in their primary care records) and repeated our analysis including these cases. We also repeated our analyses reclassifying those pregnancies in women who had their diagnosis recorded for the first time within the 12 weeks postpartum as undiagnosed $\mathrm{CD}$ (rather than diagnosed). Finally, we assessed whether there is an independent increase in the risk of adverse birth outcomes regardless of the mode of delivery. This was done by restricting our analysis to only those women who underwent a normal vaginal delivery. All analyses were carried out using Stata SE 11.2 (Stata Corp., TX, USA).

\section{Ethical statement}

This study was approved by the Independent Scientific Advisory Committee (ISAC) reference number=10_193R. 


\section{Results}

\section{$\underline{\text { Study population }}$}

Among 276,586 women in our study population, there were 364,186 singleton pregnancies resulting in a live birth or a stillbirth. We excluded $0.07 \%(\mathrm{n}=256)$ of pregnancies in women with DH without CD $(0.01 \%)$ or who had gluten-free prescriptions without any evidence of concurrent CD $(0.05 \%)$. This resulted in a total of 363,930 pregnancies which were included in the analysis. The overall proportion of pregnancies among women with $\mathrm{CD}$ was $0.25 \%$ $(892 / 363,930)$ with the median age at diagnosis of 29 years (inter quartile range 20.2-34.7).. Of these pregnancies $62 \%(\mathrm{n}=551)$ were among women with diagnosed CD and $38 \%(\mathrm{n}=341)$ among women with undiagnosed $\mathrm{CD}$. Table 1 shows the maternal characteristics for all pregnancies in women with and without $\mathrm{CD}$. Compared to women without $\mathrm{CD}$, women with CD had lower BMI, were less likely to be smokers and had a higher prevalence of diabetes. Pregnant women with diagnosed CD were slightly older than those with undiagnosed CD but otherwise had similar maternal characteristics.

\section{$\underline{\text { Pregnancy complications and adverse birth outcomes among women with CD }}$}

Table 2 shows the absolute risks of pregnancy complications and adverse birth outcomes among pregnancies in women with diagnosed and undiagnosed $\mathrm{CD}$ and those in women without CD. Overall, pregnancies in women with $\mathrm{CD}$ had slightly higher incidence of postpartum and antepartum haemorrhage, peeclampsia/eclampsia, caesarean section delivery, assisted delivery, stillbirth, preterm birth or low birth weight babies compared to pregnant women without $\mathrm{CD}$ (absolute risk difference of $<2.5 \%$ ), all of which were not statistically significant. 


\section{Diagnosed coeliac disease}

Among pregnancies in women diagnosed with $\mathrm{CD}$, we found a slightly higher risk of postpartum haemorrhage with an absolute risk (AR) of 13.2\% (Table 2) than women without CD. This corresponded to a $3.5 \%$ excess absolute risk and a $34 \%$ increased adjusted relative risk (OR 1.34 (95\% CI 1.04-1.72 compared to pregnancies in women without CD (Table 3). There was no statistically significant increased risk of pre-eclampsia/eclampsia, antepartum haemorrhage or caesarean section delivery. We observed a greater risk of assisted deliveries among those with diagnosed coeliac disease ( $A R=15 \%$ versus $12 \%$ in women without $C D)$ which corresponded to a $34 \%$ increased relative risk (Adjusted OR (aOR) 1.34, 95\% CI: 1.05-1.71) and 3\% excess absolute risk. The risk of stillbirth, preterm birth and babies born with low birth weight was similar among pregnancies in women with diagnosed CD and without CD. Finally, there was no mean difference in the birth weight of babies born to women with diagnosed CD compared to women without CD (Adjusted mean difference $=-15$ grams $95 \% \mathrm{CI}-72$ grams to 41 grams).

\section{Undiagnosed coeliac disease}

Among pregnancies in women with undiagnosed coeliac disease, we found no overall increased risk of postpartum haemorrhage, pre-eclampsia/eclampsia, antepartum haemorrhage or having an assisted delivery or emergency caesarean section (Tables 2 and 3). Compared to pregnancies among women without $\mathrm{CD}$, the risk of preterm birth was roughly similar among those with undiagnosed coeliac disease $(6.5 \%$ versus $7.6 \%)(\mathrm{aOR}=1.24$ 95\% CI 0.82-1.88). We found that pregnancies in women with undiagnosed CD resulted in babies with a mean birth weight 65 grams lower than babies born to women without $\mathrm{CD}$, however, this difference was not statistically significant at the 5\% level (95\% CI -151grams to 20 grams) after adjusting for all potential confounding factors. 


\section{$\underline{\text { Sensitivity and other analyses }}$}

Sixty seven percent of pregnant women with CD received a gluten-free prescription during the study period. Our findings for both diagnosed and undiagnosed CD remained broadly consistent when we added coeliac cases recorded solely in the secondary care data $(n=176)$ and restricted our analysis to only those cases who received a gluten-free prescription $(n=595)$ (Table 4). However we did find a statistically significant increased risk of infants with low birth weight born to mothers with $\mathrm{CD}$ compared to those without $\mathrm{CD}$. $(\mathrm{aOR}=1.83$ 95\% CI 1.05-3.17). When we included pregnancies in women with $\mathrm{CD}$ that had been classified as diagnosed due to their diagnosis being in the postpartum period as undiagnosed, our risk estimates remained unchanged (Table 5). Similarly our estimates for pregnancy complications and adverse birth outcomes remained unchanged when we restricted our analysis to pregnant women who underwent normal vaginal delivery (Table 5). This was with the exception of postpartum haemorrhage which was not associated with increased risk among women with diagnosed CD. 


\section{Discussion}

\section{$\underline{\text { Main findings }}$}

In this large nationally representative cohort of more than 360,000 singleton pregnancies resulting in a live birth or a stillbirth, we have provided contemporary, generalisable, population-based estimates of the proportion of pregnancies in England that occur in women either with a diagnosis of $\mathrm{CD}$ prior to delivery or following it and their risk of pregnancy complications and adverse birth outcomes. We found that $0.25 \%$ of pregnancies were among women who had or went on to develop CD, of which over one-third are not diagnosed until after delivery. With the exception of postpartum haemorrhage and assisted delivery we observed no increased risk of pregnancy associated complications or adverse birth outcomes among the pregnancies in women with diagnosed $\mathrm{CD}$ compared to those without the diagnosis. Similarly, we also found that undiagnosed CD is not associated with pregnancy complications and adverse birth outcomes.

\section{$\underline{\text { Strength and limitations }}$}

We have conducted one of the largest studies to determine the risk of pregnancy complications and adverse birth outcomes in CD utilising data from both primary and secondary care whilst adjusting for important confounding factors such as BMI, smoking status and maternal diabetes. Our study used an open cohort approach, with prospectively collected data from across England covering 3\% of the total UK population with a similar age and sex distribution to the population as a whole. Furthermore, HES is the primary source of maternity statistics in England where birth outcomes have been externally validated with high accuracy.(19) This makes our study findings not only generalisable to the singleton pregnancies resulting in a live birth or a stillbirth in England but also to other developed nations with similar health care systems. 
Since we used anonymised patient records and had no direct access to the patients, we were dependent on the GPs entering data accurately in the CPRD for our case validity. This is a weakness of our study as by being able to use only the available data we the lack of histological and serological information common to cohorts that have been studied in specific secondary or tertiary centres or with complete linkages to pathology systems. However because the definition of $\mathrm{CD}$ we have used is based on recording of a clinical diagnosis by the GPs it reflects the real world of clinical practice as it occurs in the general population of the UK. This, in turn, has allowed us to study a large number of pregnancies which would not otherwise be easily possible in a bespoke cohort study. Fortunately, this method of defining $\mathrm{CD}$ has been validated in general practice databases with a positive predictive value ranging between $81 \%$ and $89 \%$ which increases when prescription data are also used.(2) When we increased the specificity of our diagnosis by restricting our analysis only to cases with a supporting gluten-free prescription, our estimates remained broadly similar for both diagnosed and undiagnosed CD indicating that any misclassification inherent to our overall definition is likely to have had a small effect on our estimates. We do acknowledge that CD diagnoses recorded in inpatient data in England have not been validated. For this reason we only included them in our sensitivity for which our estimates remained unaltered.

It is important to highlight that $33 \%$ of pregnant women with $\mathrm{CD}$ diagnosis did not receive gluten-free prescriptions which may be due to a number of factors. For instance, these prescriptions are expensive and aside from during pregnancy/early postpartum (or if other comorbidities are present) women of this age do not routinely get free prescriptions in England, hence they may purchase specific gluten-free products directly. Moreover, a relatively short duration of follow-up (i.e. our inability to capture those prescriptions) and a high proportion of "prevalent" cases (i.e. women giving up those prescriptions later on after 
diagnosis) may also be contributory factors. Another limitation of this study is the lack of compliance data on a gluten-free diet among those with diagnosed CD. Like most studies done on the topic, we assumed that all women with diagnosed CD are broadly compliant with a gluten-free diet which seems reasonable given previous evidence suggesting that complete non-adherence to a gluten-free diet is uncommon among patients with CD.(20) There could of course be some misclassification in terms of children of mothers with and without CD in our study. It is likely that some mothers without $\mathrm{CD}$ in our study may have undiagnosed disease throughout the whole study period. This however should only bias our results towards the null i.e. of no increase in the risk of pregnancy complications and adverse birth outcomes.

We also recognise that our lack of complete data on BMI and birth weight could bias our estimates. However, we treated missing data as a separate category and included it in our analysis. The fact that we were able to utilise data on BMI does however give us an advantage over other studies $(3,7,8)$ in this field which have been previously unable to. We observed lower proportions of pregnant women with undiagnosed $\mathrm{CD}$ in more recent years compared to those with diagnosed $\mathrm{CD}$. This was probably due to the fact that in order to be undiagnosed, a pregnancy needs to occur earlier in the data and vice versa for those with diagnosed CD. Finally, it is important to note that our study may have limited power to show small excess risks for certain outcome (e.g. stillbirths). Therefore one cannot rule out minor risk increases associated with these outcomes due to a potential for type 2 error.

\section{Comparison with previous literature}

The overall prevalence of $\mathrm{CD}$ in our study among pregnant women was calculated to be $0.25 \%$. Whilst this proportion is much lower than most small scale hospital-based studies 
$(1 \%),(4,11)$ it is not surprising as our cases included those with a clinical diagnosis of CD as opposed to positive serology identified via screening. Our proportions are still higher than those reported by most large registry-based studies (around $0.07 \%) .(7,8)$ This may be due to their reliance on in-patient hospital data and lack of out-patient or primary care data leading to the under-estimation of the prevalence. We did not observe increased risks of preterm birth and low birth weight among those with diagnosed coeliac disease, a finding consistent with the available population based studies. $(3,7,8,11)$ Our finding of a $34 \%$ increased risk of postpartum haemorrhage and assisted deliveries among those with diagnosed CD is new as previous studies have not reported this.

Overall we found no increased risk of low birth weight and preterm birth among undiagnosed coeliac mothers. This finding is consistent with a multicentre study conducted by Greco et al.(10) where 5,055 mothers were screened for CD, of which 51(\%) had a positive result. The study concluded that undiagnosed $\mathrm{CD}$, while common in pregnancy is not associated with an excess risk of preterm delivery, low birth weight, abortion or intrauterine growth restriction. Our findings do however contradict some of the largest registry based studies to date. $(3,7,8)$ For instance, Ludvigsson et al(7) in their population-based study demonstrated that women with undiagnosed $\mathrm{CD}$ were $71 \%$ more likely to have preterm birth and over 2-times more likely to have infants with low birth weight. These different findings to ours could be because the cases identified through hospital-based registers may suffer from a more severe form of disease than those diagnosed within the general population. Our study showed no increased risk of caesarean section in the undiagnosed CD group in contrast to an increased risk among this group in Swedish data(7). One explanation could be the difference in the medical indication and the incidence of caesarean sections in the UK and Sweden (26\%(21) versus $17 \%(22))$ 
The only persistently increased risk we observed was a $34 \%$ increased risk of postpartum haemorrhage and assisted deliveries among those with diagnosed CD which has not been reported before. This may be due to the higher proportion of women undergoing assisted delivery which may increase the likelihood of postpartum haemorrhage compared with normal vaginal delivery.(23) This increased risk in women with diagnosed CD may therefore be due to more assisted deliveries rather than disease related per se.

\section{$\underline{\text { Conclusion and implications }}$}

Most women with CD diagnosed either before or after pregnancy will have a pregnancy and delivery that is not complicated by an adverse event.Our findings do suggest that among women already diagnosed with CD there may be a small increase in the risk of a pregnancy being complicated by a postpartum haemorrhage but the reasons for this are not entirely clear. Overall our results should be reassuring to both women and practitioners. 
Tables

Table 1: Basic characteristic of pregnancies among women with and without coeliac disease

\begin{tabular}{|c|c|c|c|c|c|c|c|c|}
\hline \multirow[t]{2}{*}{ Variables } & \multicolumn{2}{|c|}{$\begin{array}{c}\text { Without CD } \\
(\text { Total }=363,038)\end{array}$} & \multicolumn{2}{|c|}{$\begin{array}{c}\text { With CD } \\
\text { (Total=892) }\end{array}$} & \multicolumn{2}{|c|}{$\begin{array}{c}\text { Diagnosed CD } \\
\text { (Total=551) }\end{array}$} & \multicolumn{2}{|c|}{$\begin{array}{c}\text { Undiagnosed CD } \\
\text { (Total=341) }\end{array}$} \\
\hline & n. & $\%$ & $\mathbf{n}$ & $\%$ & $n$ & $\%$ & $\mathrm{n}$ & $\%$ \\
\hline \multicolumn{9}{|l|}{ Age at delivery } \\
\hline $15-19$ years & 21,182 & 5.8 & 38 & 4.3 & 23 & 4.2 & 15 & 4.4 \\
\hline 20-24 years & 62,217 & 17.1 & 93 & 10.4 & 57 & 10.3 & 36 & 10.6 \\
\hline 25-29 Years & 95,665 & 26.4 & 223 & 25.0 & 132 & 24.0 & 91 & 26.7 \\
\hline 30-34 years & 110,712 & 30.5 & 308 & 34.5 & 171 & 31.0 & 137 & 40.2 \\
\hline 35-39 years & 60,911 & 16.8 & 176 & 19.7 & 129 & 23.4 & 47 & 13.8 \\
\hline 40-44 years & 12,351 & 3.4 & 54 & 6.1 & 39 & 7.1 & 15 & 4.4 \\
\hline \multicolumn{9}{|c|}{ Body Mass Index kg/m² } \\
\hline Normal(18.5-24.9) & 158,324 & 43.6 & 438 & 49.1 & 269 & 48.8 & 169 & 49.6 \\
\hline Underweight(<18.5) & 11,802 & 3.3 & 63 & 7.1 & 39 & 7.1 & 24 & 7.0 \\
\hline Overweight(25-29.9) & 65,726 & 18.1 & 137 & 15.4 & 94 & 17.1 & 43 & 12.6 \\
\hline Obese(>=30) & 41,109 & 11.3 & 74 & 8.3 & 40 & 7.3 & 34 & 10.0 \\
\hline Missing & 86,077 & 23.7 & 180 & 20.2 & 109 & 19.8 & 71 & 20.8 \\
\hline \multicolumn{9}{|l|}{ Smoking status } \\
\hline smoker & 79,782 & 22.0 & 146 & 16.4 & 100 & 18.1 & 46 & 13.5 \\
\hline Non-smoker & 283,256 & 78.0 & 746 & 83.6 & 451 & 81.9 & 295 & 86.5 \\
\hline \multicolumn{9}{|l|}{ Ethnicity } \\
\hline White & 264,312 & 72.8 & 684 & 76.7 & 427 & 77.5 & 257 & 75.4 \\
\hline Non-white & 37,148 & 10.2 & 55 & 6.2 & 30 & 5.4 & 25 & 7.3 \\
\hline Missing & 61,578 & 17.0 & 153 & 17.2 & 94 & 17.1 & 59 & 17.3 \\
\hline \multicolumn{9}{|l|}{ Pre-existing diabetes } \\
\hline No & 359,094 & 98.9 & 852 & 95.5 & 525 & 95.3 & 327 & 95.9 \\
\hline Yes & 3,944 & 1.1 & 40 & 4.6 & 26 & 4.8 & 14 & 4.2 \\
\hline \multicolumn{9}{|l|}{ Calendar year } \\
\hline $1997-2001$ & 72,837 & 20.1 & 204 & 22.9 & 81 & 14.7 & 123 & 36.1 \\
\hline $2002-2007$ & 127,055 & 35.0 & 321 & 36.0 & 171 & 31.0 & 150 & 44.0 \\
\hline 2007-2012 & 163,146 & 44.9 & 367 & 41.1 & 299 & 54.3 & 68 & 19.9 \\
\hline \multicolumn{9}{|l|}{ SES quintile } \\
\hline 1 (Least deprived) & 54,305 & 15 & 168 & 18.8 & 102 & 18.5 & 66 & 19.4 \\
\hline 2 & 75,309 & 20.7 & 210 & 23.5 & 123 & 22.3 & 87 & 25.5 \\
\hline 3 & 70,955 & 19.5 & 178 & 20.0 & 111 & 20.1 & 67 & 19.6 \\
\hline 4 & 83,323 & 23 & 179 & 20.1 & 106 & 19.2 & 73 & 21.4 \\
\hline 5 (Most deprived) & 79,146 & 21.8 & 157 & 17.6 & 109 & 19.8 & 48 & 14.1 \\
\hline
\end{tabular}

${ }^{1}$ Type 1 or type 2 diabetes before conception 
Table 2: Absolute risks of pregnancy complication and adverse birth outcome among women with and without CD.

\begin{tabular}{|c|c|c|c|c|c|c|c|c|}
\hline \multirow[t]{2}{*}{ Variables } & \multicolumn{2}{|c|}{$\begin{array}{c}\text { Without CD } \\
\text { (Total }=363,038)\end{array}$} & \multicolumn{2}{|c|}{$\begin{array}{c}\text { With CD } \\
\text { Overall } \\
\text { (Total=892) }\end{array}$} & \multicolumn{2}{|c|}{$\begin{array}{c}\text { Diagnosed CD } \\
\text { (Total }=551 \text { ) }\end{array}$} & \multicolumn{2}{|c|}{$\begin{array}{c}\text { Undiagnosed CD } \\
\text { (Total }=\mathbf{3 4 1 )}\end{array}$} \\
\hline & $\mathrm{n}$ & $\%$ & n & $\%$ & $n$ & $\%$ & $\mathrm{n}$ & $\%$ \\
\hline \multicolumn{9}{|l|}{ Pregnancy complications } \\
\hline Postpartum haemorrhage ${ }^{3}$ & 35,278 & 9.7 & 102 & 11.4 & 73 & 13.2 & 29 & 8.5 \\
\hline Preeclampsia/eclampsia & 8,270 & 2.3 & 24 & 2.7 & 14 & 2.5 & 10 & 2.9 \\
\hline Antepartum haemorrhage & 17,074 & 4.7 & 49 & 5.5 & 32 & 5.8 & 17 & 5.0 \\
\hline \multicolumn{9}{|l|}{ Mode of delivery } \\
\hline Normal vaginal delivery & 233,524 & 64.3 & 523 & 58.6 & 315 & 57.2 & 208 & 61.0 \\
\hline Assisted & 43,934 & 12.1 & 127 & 14.2 & 85 & 15.4 & 42 & 12.3 \\
\hline Elective caesarean & 35,443 & 9.8 & 107 & 12.0 & 61 & 11.1 & 46 & 13.5 \\
\hline Emergency caesarean & 50,137 & 13.8 & 135 & 15.1 & 90 & 16.3 & 45 & 13.2 \\
\hline \multicolumn{9}{|l|}{ Birth outcomes } \\
\hline Live birth & 361,471 & 99.6 & 886 & 99.3 & 547 & 99.3 & 339 & 99.4 \\
\hline Stillbirth & 1,567 & 0.4 & 6 & 0.7 & 4 & 0.7 & 2 & 0.6 \\
\hline \multicolumn{9}{|l|}{ Length of gestation } \\
\hline Normal & 305,424 & 84.1 & 733 & 82.2 & 457 & 82.9 & 276 & 80.9 \\
\hline Pre-term & 23,595 & 6.5 & 68 & 7.6 & 42 & 7.6 & 26 & 7.6 \\
\hline Prolonged & 34,019 & 9.4 & 91 & 10.2 & 52 & 9.4 & 39 & 11.4 \\
\hline \multicolumn{9}{|l|}{ Birth weight } \\
\hline Live birth (2500-4500 grams) & 272,754 & 75.2 & 659 & 73.9 & 426 & 77.3 & 233 & 68.3 \\
\hline Macrosomia (above 4500 grams) & 5,296 & 1.5 & 7 & 0.8 & 5 & 0.9 & 2 & 0.6 \\
\hline Low birth weight $<2500$ grams & 16,439 & 4.5 & 48 & 5.4 & 29 & 5.3 & 19 & 5.6 \\
\hline Missing & 68,157 & 18.8 & 178 & 20.0 & 91 & 16.5 & 87 & 25.5 \\
\hline
\end{tabular}


Table 3: Odds ratios of pregnancy complications and adverse birth outcomes among women with CD compared to those without CD

\begin{tabular}{|c|c|c|c|}
\hline Variables & $\begin{array}{c}\text { CD } \\
\text { Overall }\end{array}$ & Diagnosed CD & Undiagnosed CD \\
\hline & OR (95\% Cl) & OR (95\% Cl) & OR (95\% Cl) \\
\hline & Adjusted* & Adjusted $^{*}$ & Adjusted* \\
\hline \multicolumn{4}{|l|}{ Pregnancy complication } \\
\hline Postpartum haemorrhage ${ }^{1}$ & $1.19(0.97-1.47)$ & $1.34(1.04-1.72)$ & $0.94(0.63-1.40)$ \\
\hline Pre-eclampsia/eclampsia ${ }^{1}$ & $1.20(0.75-1.91)$ & $1.16(0.65-2.05)$ & $1.25(0.59-2.76)$ \\
\hline Antepartum haemorrhage $^{1}$ & $1.22(0.92-1.63)$ & $1.28(0.89-1.83)$ & $1.14(0.70-1.84)$ \\
\hline \multicolumn{4}{|l|}{ Mode of delivery ${ }^{2}$} \\
\hline Assisted & $1.21(0.99-1.40)$ & $1.34(1.05-1.71)$ & $1.02(0.73-1.41)$ \\
\hline Elective caesarean & $1.20(0.95-1.53)$ & $1.10(0.81-1.40)$ & $1.39(0.94-2.05)$ \\
\hline Emergency caesarean & $1.16(0.94-1.43)$ & $1.26(0.98-1.64)$ & $1.00(0.71-1.42)$ \\
\hline \multicolumn{4}{|l|}{ Birth outcome } \\
\hline Stillbirth ${ }^{3}$ & $1.59(0.71-3.54)$ & $1.70(0.63-4.54)$ & $1.42(0.35-5.64)$ \\
\hline \multicolumn{4}{|l|}{ Length of gestation ${ }^{4}$} \\
\hline Pre-term & $1.17(0.90-1.53)$ & $1.14(0.83-1.60)$ & $1.24(0.82-1.87)$ \\
\hline Prolonged & $1.16(0.92-1.47)$ & $1.08(0.79-1.47)$ & $1.31(0.92-1.85)$ \\
\hline \multicolumn{4}{|l|}{ Birth weight ${ }^{5}$} \\
\hline Macrosmia (>4500 grams) & $0.52(0.24-1.09)$ & $0.58(0.24-1.41)$ & $0.41(0.10-1.62)$ \\
\hline Low birth weight (<2500 grams) & $1.22(0.89-1.68)$ & $1.15(0.76-1.74)$ & $1.36(0.83-2.24)$ \\
\hline Missing & $1.07(0.89-1.29)$ & $0.92(0.72-1.19)$ & $1.34(1.00-1.70)$ \\
\hline
\end{tabular}

${ }^{*}$ Adjusted for smoking status, age, ethnicity, diabetes, BMI, social class and calendar year

${ }^{2}$ Multi-nominal regression analysis, risks relative to vaginal delivery

${ }^{3}$ Analysis based on live births

${ }^{4}$ Multi-nominal regression analysis, analysis based on pregnancies with normal gestational length

${ }^{5}$ Multi-nominal regression analysis, analysis based on live births with normal birth weight 
Table 4: Sensitivity analysis: Risk of pregnancy complications and adverse birth outcomes among women with CD compared to those without CD

\begin{tabular}{|c|c|c|c|c|}
\hline \multirow[b]{2}{*}{ Variables } & \multicolumn{2}{|c|}{$\begin{array}{l}\text { Restrictive Coeliac definition* } \\
\text { (Total } C D=595) \\
\text { Adjusted Odds ratio }(95 \% \mathrm{Cl})\end{array}$} & \multicolumn{2}{|c|}{$\begin{array}{l}\text { Addition of Coeliac cases from secondary care } \\
\text { (Total } \mathrm{CD}=1,068) \\
\text { Adjusted Odds ratio }(95 \% \mathrm{Cl}) \\
\end{array}$} \\
\hline & $\begin{array}{c}\text { Diagnosed CD } \\
\quad(n=371)\end{array}$ & $\begin{array}{c}\text { Undiagnosed CD } \\
(n=224)\end{array}$ & $\begin{array}{l}\text { Diagnosed CD } \\
(n=604)\end{array}$ & $\begin{array}{l}\text { Undiagnosed CD } \\
(n=464)\end{array}$ \\
\hline Postpartum haemorrhage ${ }^{1}$ & $1.53(1.14-2.05)$ & $0.89(0.54-1.46)$ & $1.31(1.03-1.68)$ & $0.98(0.64-1.28)$ \\
\hline Pre-eclampsia/eclampsia ${ }^{1}$ & $0.85(0.48-1.78)$ & $1.27(0.45-3.51)$ & $1.16(0.67-2.00)$ & $1.23(0.63-2.40)$ \\
\hline Antepartum haemorrhage ${ }^{1}$ & $1.24(0.80-1.93)$ & $1.11(0.61-2.02)$ & $1.30(0.92-1.84)$ & $1.29(0.87-1.91)$ \\
\hline Assisted delivery ${ }^{2,6}$ & $1.24(0.92-1.69)$ & $0.98(0.65-1.48)$ & $1.32(1.04-1.68)$ & $0.96(0.72-1.28)$ \\
\hline Elective caesarean 2,6 & $1.11(0.78-1.57)$ & $1.13(0.68-1.86)$ & $1.13(0.86-1.50)$ & $1.30(0.93-1.83)$ \\
\hline Emergency caesarean ${ }^{2,6}$ & $1.11(0.78-1.57)$ & $0.94(0.61-1.43)$ & $1.24(0.96-1.59)$ & $0.86(0.63-1.18)$ \\
\hline Stillbirth ${ }^{3}$ & $1.24(0.31-4.97)$ & $2.11(0.53-8.35)$ & $1.96(0.81-4.72)$ & $2.08(0.78-5.54)$ \\
\hline Pre-term birth 4,6 & $1.12(0.74-1.69)$ & $1.22(0.73-2.04)$ & $1.12(0.81-1.56)$ & $1.31(0.93-1.84)$ \\
\hline Low birth weight $(<2500 \text { grams })^{5,6}$ & $1.03(0.60-1.74)$ & $1.83(1.05-3.17)$ & $1.08(0.81-1.46)$ & $1.50(1.00-2.24)$ \\
\hline
\end{tabular}

*Coeliac diagnosis with gluten-free prescriptions.

Adjusted for smoking status, age, ethnicity, diabetes, BMI, social class and calendar year

${ }^{1}$ Analysis based on pregnancy without complication under study

${ }^{2}$ Analysis based on normal vaginal delivery

${ }^{3}$ Analysis based on live birth

${ }^{4}$ Analysis based on normal gestational length

${ }^{5}$ Analysis based on live birth with normal weight

${ }^{6}$ Results from multi-nominal regression analysis (RRRs, 95\% Cl) 
Table 5: Sensitivity analysis: Risk of pregnancy complications and adverse birth outcomes among women with CD compared to those without CD

\begin{tabular}{|c|c|c|c|c|}
\hline \multirow[b]{2}{*}{ Variables } & \multicolumn{2}{|c|}{$\begin{array}{l}\text { Treating postpartum coeliac as incident case } \\
\text { (Total } C D=892) \\
\text { Adjusted Odds ratio }(95 \% \mathrm{Cl})\end{array}$} & \multicolumn{2}{|c|}{$\begin{array}{c}\text { Restricting analysis to only those who underwent } \\
\text { normal vaginal delivery } \\
\text { (Total } C D=523) \\
\text { Adjusted Odds ratio }(95 \% \mathrm{Cl})\end{array}$} \\
\hline & $\begin{array}{c}\text { Diagnosed CD } \\
(n=549)\end{array}$ & $\begin{array}{c}\text { Undiagnosed CD } \\
(n=343)\end{array}$ & $\begin{array}{l}\text { Diagnosed CD } \\
(n=371)\end{array}$ & $\begin{array}{l}\text { Undiagnosed CD } \\
(n=224)\end{array}$ \\
\hline Postpartum haemorrhage ${ }^{1}$ & $1.34(1.04-1.73)$ & $0.94(0.62-1.39)$ & $1.22(0.81-1.84)$ & $0.58(0.27-1.25)$ \\
\hline Pre-eclampsia/eclampsia ${ }^{1}$ & $1.16(0.66-2.05)$ & $1.24(0.56-2.75)$ & $0.49(0.12-2.00)$ & $2.12(0.83-5.39)$ \\
\hline Antepartum haemorrhage ${ }^{1}$ & $1.20(0.83-1.73)$ & $1.27(0.80-2.01)$ & $1.36(0.84-2.20)$ & $1.16(0.62-2.18)$ \\
\hline Assisted delivery ${ }^{2,6}$ & $1.34(1.05-1.72)$ & $1.01(0.73-1.40)$ & - & - \\
\hline Elective caesarean ${ }^{2,6}$ & $1.10(0.82-1.48)$ & $1.38(0.93-2.04)$ & - & - \\
\hline Emergency caesarean ${ }^{2,6}$ & $1.26(0.97-1.63)$ & $1.02(0.72-1.43)$ & - & - \\
\hline Stillbirth ${ }^{3}$ & $1.27(0.41-3.92)$ & $2.13(0.69-6.58)$ & $0.65(0.09-4.63)$ & 1.04 (0.15-7.19) \\
\hline Pre-term birth ${ }^{4,6}$ & $1.12(0.78-1.56)$ & $1.29(0.86-1.93)$ & $0.51(0.26-0.99)$ & $1.37(0.80-2.35)$ \\
\hline Low birth weight $(<2500 \text { grams) })^{5,6}$ & $1.11(0.73-1.69)$ & $1.43(0.88-2.32)$ & $0.59(0.28-1.27)$ & $1.47(0.76-2.83)$ \\
\hline
\end{tabular}

\footnotetext{
${ }^{1}$ Analysis based on pregnancy without complication under study

${ }^{2}$ Analysis based on normal vaginal delivery

${ }^{3}$ Analysis based on live birth

${ }^{4}$ Analysis based normal gestational length

${ }^{5}$ Analysis based on live birth with normal birth weight

${ }^{6}$ Results from multi-nominal regression analysis
}

Adjusted for smoking status, age, ethnicity, diabetes, BMI, social class and calendar year 


\section{Acknowledgements}

\section{Conflict-of-interest disclosure:}

No authors have conflicts of interest to declare.

\section{Study Contributions}

AAS and JW conceived the idea for the study, with KMF, CC, JFL, NND, LB and LJT also making important contributions to the design of the study. AAS carried out the data management and analysis and wrote the first draft of the manuscript. All authors were involved in the interpretation of the data, contributed towards critical revision of the manuscript and approved the final draft. AAS had full access to all of the data and final responsibility for the decision to submit for publication.

\section{Financial disclosure}

CORE/Coeliac UK; JW is funded by a University Of Nottingham/Nottingham University Hospitals NHS Trust Senior Clinical Research Fellowship 


\section{References}

1. Dubé C, Rostom A, Sy R, Cranney A, Saloojee N, Garritty C, et al. The prevalence of celiac disease in average-risk and at-risk Western European populations: a systematic review. Gastroenterology. 2005;128(4):S57-S67.

2. West J. Coeliac disease: studies of its frequency and consequence. PhD Thesis: The University of Nottingham; 2005.

3. Norgard B, Fonager K, Sorensen HT, Olsen J. Birth outcomes of women with celiac disease: a nationwide historical cohort study. Am J Gastroenterol. 1999;94(9):2435-40.

4. Ciacci C, Cirillo M, Auriemma G, Di Dato G, Sabbatini F, Mazzacca G. Celiac disease and pregnancy outcome. Am J Gastroenterol. 1996;91(4):718-22.

5. Ludvigsson JF, Ludvigsson J. Coeliac disease in the father affects the newborn. Gut. 2001;49(2):169-75.

6. Sheiner E, Peleg R, Levy A. Pregnancy outcome of patients with known celiac disease. European Journal of Obstetrics \& Gynecology and Reproductive Biology. 2006;129(1):41-5.

7. Ludvigsson JF, Montgomery SM, Ekbom A. Celiac disease and risk of adverse fetal outcome: a population-based cohort study. Gastroenterology. 2005;129(2):454-63.

8. Khashan AS, Henriksen TB, Mortensen PB, McNamee R, McCarthy FP, Pedersen $\mathrm{MG}$, et al. The impact of maternal celiac disease on birthweight and preterm birth: a Danish population-based cohort study. Hum Reprod. 2010;25(2):528-34.

9. Tata L, Card T, Logan R, Hubbard R, Smith C, West J. Fertility and pregnancyrelated events in women with celiac disease: a population-based cohort study. Gastroenterology. 2005;128(4):849-55.

10. Greco L, Veneziano A, Di Donato L, Zampella C, Pecoraro M, Paladini D, et al. Undiagnosed coeliac disease does not appear to be associated with unfavourable outcome of pregnancy. Gut. 2004;53(1):149-51.

11. Martinelli P, Troncone R, Paparo F, Torre P, Trapanese E, Fasano C, et al. Coeliac disease and unfavourable outcome of pregnancy. Gut. 2000;46(3):332-5.

12. Clinical Practice Research Database. [19/04/2013]; Available from: http://www.cprd.com/intro.asp.

13. Lo Re V, Haynes K, Forde KA, Localio AR, Schinnar R, Lewis JD. Validity of The Health Improvement Network (THIN) for epidemiologic studies of hepatitis C virus infection. Pharmacoepidemiology and drug safety. 2009;18(9):807-14.

14. Hospital Episode Statistics. [19/04/2013]; Available from: http://www.hesonline.nhs.uk.

15. Eaton SC, Williams TJ, Puri S, VanStaa T. The feasibility of linking the English Hospital Episode Statistics to the GPRD. Pharmacoepidemiol Drug Saf 2008;17:S214. 
16. Crooks C. Epidemiology of upper gastrointestinal bleeding studying its causes and outcomes using case control studies and surivival analyses. Ph.D. Thesis. : University of Nottingham; 2013.

17. Saunders C, Abel G, El Turabi A, Ahmed F, Lyratzopoulos G. Accuracy of routinely recorded ethnic group information compared with self-reported ethnicity: evidence from the English Cancer Patient Experience survey. BMJ open. 2013;3(6).

18. Jordan H, Roderick P, Martin D. The Index of Multiple Deprivation 2000 and accessibility effects on health. J Epidemiol Community Health. 2004;58(3):250-7.

19. Dattani N, Datta-Nemdharry P, Macfarlane A. Linking maternity data for England 2007: methods and data quality. Health Statistics Quarterly. 2012;53.

20. Hall N, Rubin G, Charnock A. Systematic review: adherence to a gluten-free diet in adult patients with coeliac disease. Aliment Pharmacol Ther. 2009;30(4):315-30.

21. The Information Center. NHS Maternity Statistics - England 2009-2010. 2012 [12/12/2013]; Available from: http://www.hscic.gov.uk/catalogue/PUB02111.

22. Gibbons L, Belizan J, Lauer A, Betran A, Merialdi M, Althabe F. The Global Numbers and Costs of Additionally Needed and Unnecessary Caesarean Sections Performed per Year: Overuse as a Barrier to Universal Coverage. World Health report [Internet]. 2010; Background $\quad$ paper $30 . \quad$ Available from: http://www.who.int/healthsystems/topics/financing/healthreport/30C-sectioncosts.pdf.

23. COMBS CA, Murphy EL, Laros Jr RK. Factors associated with postpartum hemorrhage with vaginal birth. Obstet Gynecol. 1991;77(1):69-76. 